\title{
Application of a Housing Technology Assessment Simulation Platform in Regulation R\&D
}

\author{
S. Rasoul Asaee ${ }^{1}$, Alex Ferguson ${ }^{1}$, Adam Wills ${ }^{2}$ \\ ${ }^{1}$ Natural Resources Canada, CanmetENERGY-Ottawa, Ottawa, ON, Canada \\ ${ }^{2}$ National Research Council, Ottawa, ON, Canada
}

\begin{abstract}
This paper presents an optimization model that will be used for the impact analysis of new net zero energy ready model building codes, and to support the local authorities for the adoption of new building codes. New archetypes representing new single detached and double/row house for eight major housing markets across Canada were developed. A case study was conducted using the new archetypes to identify which building components were significant sources of heat loss when constructed to Canadian National Building Code minimums. Increasing envelope airtightness was then explored as an energy conservation measure.
\end{abstract}

\section{Introduction}

The Pan-Canadian Framework on Clean Growth and Climate Change (Environment and Climate Change Canada, 2016) is the collective approach of federal, provincial, and territorial governments towards climate change mitigation. Key activities under the framework include development of $(i)$ Net-Zero Energy Ready (NZE-R) model building codes for new buildings and (ii) separate codes for alterations of existing buildings. Conventional approaches for code renewal that focus on incremental improvements of new construction requirements may not satisfy these ambitious new goals.A NZE-R building incorporates a combination of energy saving measures, high efficiency energy technologies, and renewable energy generation. Advances in renewable/alternative energy technologies, and innovations in building envelope design, provide a large number of options for design and construction of net zero energy buildings. As such, the design of an affordable NZE-R building is a complicated problem.

For these reasons, local authorities and industry scrutinize the cost effectiveness of future codes. As codes are renewed to deliver greater energy savings, they may impose greater capital investment and greater risk that the energy benefits will not be realized.

These risks impede effective renewal of the codes. $\mathrm{Au}-$ thorities are reluctant to adopt future codes that may impose unintended consequences on homeowners or the construction industry. Furthermore, future codes that increase capital costs while not delivering the promised changes erodes public trust in the building code and enforcement authorities.

\section{Background}

In 2008, Natural Resources Canada (NRCan) developed new archetypes to support design and assessment of the ENERGY STAR for New Homes (ESNH) program in Canada. A set of synthetic archetypes was developed using an "averaging technique" (Parekh, 2005). The averaging technique consists of analysing statistical data of building stock and the development of an average building which possesses characteristics of a mean statistical building. The average building may be a real building or an abstract building. About 6000 records from the EnerGuide for Housing Database (EGHD), covering new construction between 2002 and 2007, was reviewed for that purpose. NRCan initially intended to develop two archetypes, a single family home and a low-rise detached building. However, the 6000 house records exhibited a wide diversity of house characteristics such as shape, number of storeys, floor area, and foundation. This variation led NRCan to develop nine additional archetypes. The resulting set is generally known as the "NRCan 11 archetypes". The ESNH analysis showed that the energy consumption of archetype \#4 was close to an average of energy consumption of all 11 archetypes. In subsequent work, archetype \#4 was exclusively used for costing analysis of the ESNH and R-2000 Standards. During development of the 2012 National Building Code energy requirements, the code committee adopted the NRCan 11 archetypes for the development of prescriptive requirements for houses and small buildings. To expedite the cost and benefit analysis, the Canada Codes Commission elected to base the analysis on a single archetype (archetype \#4) and using blended, average rates for energy costs. The lead researcher on that study noted the limitations of the approach, and recommended more thorough approaches for future work (Proskiw, 2011):

"This cost benefit analysis was completed as an exercise to obtain an indication of the energy impact of the proposed changes on a national base. Although 
specific locations were used in the analysis, this cost benefit study cannot be taken as a true reflection of the cost or energy savings for those locations."

"In order to achieve a true representation of the impact of the proposed requirements in a specific region, it would be paramount that the analysis be performed using the respective regional context of current construction baseline, cost of construction materials and utility rates as well as common housing archetypes. The energy target data could then be used to calculate the benefits for an actual region."

Amann (2014) and Perry (2018) studies indicated that building codes can evolve to ensure that majority of homes and buildings fulfill the zero energy requirements. Asaee et al. (2019) used a bottom-up housing stock model to study the impact of various retrofit scenarios for existing Canadian houses. The results indicated that the the proposed retrofit scenarios were not sufficient for the large scale conversion of existing Canadian houses into net zero energy buildings. Wills et al. (2016) used a housing stock modeling approach to evaluate the impact of photovoltaic (PV) system retrofit in existing communities in four locations across Canada. Results indicated that the PV retrofit is not sufficient to convert existing communities into net zero energy community.

\section{Objective}

This study aims to present an optimization model, which is developed using the whole building simulation technique, that is quick, robust, and reliable. The model will be used to evaluate the impact and unintended consequences of various energy efficiency measures for the next generation of building codes in Canada. A case study is presented to illustrate the application of the model for code analysis.

\section{Methods}

The Housing Technology Assessment Platform (HTAP), developed to identify optimized technoeconomically feasible approaches for housing design, can be used for code analysis. HTAP brings together building performance simulation (BPS) software, building stock data, energy conservation measures, rulesets and energy targets, economic data, and cloud computing to analyze numerous technology combinations and identify optimized design scenarios. The scope of HTAP is the housing and small buildings (also known as the Part 9 of the building code in Canada (CCBFC, 2015)).

\section{Building Simulation Engine}

HTAP incorporates a house-as-a-system approach where every design scenario is modeled as a complete house in an annual energy analysis. HTAP uses HOT2000 (NRCan, 2018c) and ESP-r (ESRU, 2018) as its building simulation engines.

NRCan developed, distributes, and maintains HOT2000 for residential building performance sim- ulation in Canada. HOT2000 estimates the energy requirements (i.e. space heating, water heating, appliances, and lighting) of a building using the monthly energy balance technique. The monthly energy balance includes monthly and hourly bin analyses of specific building components and mechanical systems (NRCan, 2018c). HOT2000 has been validated through real building monitoring and other detailed simulation programs (Haltrecht and Fraser, 1997). Parekh et al. (2018) conducted a study to evaluate the latest version of HOT2000 in accordance with ASHRAE Standard 140-2014 (ASHRAE, 2014).

HOT2000 has been extensively used for energy rating, code compliance, and incentive programs in the Canadian housing sector. The Canadian National Building Code (NBC) provides a performance pathway that requires a builder to demonstrate the house energy consumption is less than or equal to the NBC's requirement (CCBFC, 2015). Currently HOT2000 is the main software used by the residential building industry for this purpose. Therefore, HOT2000 is selected for the analysis in this work.

\section{Weather Data}

HOT2000 contains complete monthly and annual climate data for 126 locations across Canada (NRCan, 2018c). HTAP uses the majority of this weather data to evaluate the impact of each design scenario in various climatic conditions across Canada. The heating degree days (HDD) of the specified locations is between 2650 and 12360. NBC (CCBFC, 2015) splits locations into six climate regions based on the HDD (base $18^{\circ} \mathrm{C}$ ) and devise specific requirements for buildings in each region. The climate regions are:

- Zone 4: HDD < 3000

- Zone 5: $3000 \leq \mathrm{HDD} \leq 3999$

- Zone 6: $4000 \leq \mathrm{HDD} \leq 4999$

- Zone 7A: $5000 \leq \mathrm{HDD} \leq 5999$

- Zone 7B: $6000 \leq \mathrm{HDD} \leq 6999$

- Zone 8: $7000 \leq \mathrm{HDD}$

\section{Cost Data}

HTAP uses cost data from the Local Energy Efficiency Partnerships (LEEP) program (NRCan, 2018a) to estimate the cost of energy upgrades. The main steps in the LEEP approach are:

1. Builder Planning Workshop. A group of leading builders select 4-6 options that they believe are likely the most suitable for their region.

2. LEEP Technology Forum. The industry experts and manufacturers are invited to answer questions and concerns of builders regarding the key challenges to use the selected technologies, specifications for detailed costing, and supply, construction and post-construction support. All regional builders can participate in the technology forums.

3. Field Trials. Some builders choose to adopt new technologies to build higher performance houses. 
4. Sharing Builder Experiences. Builders share their experience and challenges for implementing solutions in each region.

As a result, LEEP has an extensive database of suitable technologies for each region. Cost data for each technology is collected from actual builders and suppliers. Hence, the cost data is deemed to be reliable. HTAP accumulates the cost of individual components to estimate the overall costs of each design scenario. Local energy prices are used to estimate the operating cost of each resulting house. In addition, HTAP provides tools to conduct sensitivity analyses on energy prices and cost analyses of conservation measures.

\section{Design Option Library}

HTAP takes an archetype as a base case and uses a wide range of options to create multiple design scenarios to upgrade the house. Currently the upgrade categories include: ( $i$ ) air tightness, (ii) walls, ceiling, foundation, doors, windows, and skylight insulation, (iii) heating, ventilating and air conditioning (HVAC), and domestic hot water heating systems, (iv) base-loads including appliances, lighting, and plug load, and $(v)$ building orientation. Each upgrade category consists of several options. HTAP automatically modifies the input files to add/replace selected options.

\section{Automation and Optimization Technique}

HTAP allows the user to apply energy conservation measures to each archetype, and evaluate the cumulative impact of several upgrades in each location. A unique feature of HTAP is the built-in ruleset and energy targets. This feature automatically applies the requirements of codes and energy conservation programs on each archetype to evaluate the impact of those rulesets on energy performance of new houses. HTAP uses a parameter sweep to generate all possible scenarios to design a building using the selected energy efficiency measures and mechanical systems. HTAP significantly increases the speed with which building models are generated, batch simulations are commenced, and results are extracted.

HTAP generates techno-economic data such as energy savings, greenhouse gas (GHG) emissions, investment costs, and operating cost savings for each measure as well as a combination of measures. Results can be analyzed to identify the maximum possible energy savings and GHG emissions reduction for a given investment cost. In addition, it will indicate potential paths to the NZE-R status for individual archetypes in each region.

\section{Building Archetypes}

To aid in the design and assessment of the NZE$\mathrm{R}$ code for new construction, NRCan developed 240 new housing archetypes for eight major Canadian markets across Canada. These archetypes were created using statistical methods, and reflect the best- available data on the energy characteristics of contemporary Canadian housing. The main characteristics of the new archetypes are:

1. Reflect most recent housing data,

2. Account for regional differences,

3. Contain various types of housing,

4. Support new analysis methods using HTAP and cloud-computing techniques.

Guiding Principles. Even though this project seeks to develop a more comprehensive set of archetypes that better represent the variation in Canadian housing, the archetypes themselves must be an approximation of the actual homes being constructed in Canada. Where compromises were required, NRCan adhered to the following guiding principles:

- The archetypes would be drawn from real homes built across Canada. The sampling method developed by Swan et al. (2009) would inspire this work; NRCan would adapt the method to reflect the data available for new housing,

- Each region would be represented by the same number of archetypes (15 detached, 15 attached), regardless of its significance in home construction activity. This approach ensures that provinces have a useful set of results to examine for their own NZE-R code development. Regional scaling factors would be provided to permit scaling energy impact results for nation-wide estimates,

- Archetypes would be chosen to ensure prevalent features (such as scissor ceilings, walk-out basements) are represented in as many regions as possible, even if this meant that homes with this feature would be statistically over-represented in a given regions archetypes.

Data Sources. To develop archetypes for new construction, researchers require information about: $(i)$ type, size and shape of homes being built across Canada, (ii) energy-related characteristics of those homes (including window area, ceiling types, foundation configurations), and (iii) representation of those homes in Canadian construction activity. While no single database provides all of this information, the relevant data can be consolidated from multiple sources. The EGHD (NRCan, 2018b) contains housing audit data and HOT2000 analysis collected by NRCan's various housing programs over the last 20 years. Currently, the EGHD contains over 2,000,000 audit records (including pre- and post-retrofit audit data), representing approximately 1,000,000 unique dwellings in Canada. Each audit record contains over 200 data points, describing the location, physical measurements and HOT2000 analysis estimates for the home. Audit data is collected when homeowners and home-builders participate in one of NRCan's voluntary programs.

While the EGHD is extensive (representing audits 
from over one million homes), three key requirements greatly limited the number of records that were available for this work:

1. The scope of the archetypes is new construction; which limited the available data to records from the R-2000 (NRCan, 2012), ESNH, and Energuide for New Houses programs,

2. A key objective was to represent contemporary homes; for that reason only records for homes built after 2015 were used,

3. Another objective was to ensure compatibility with HTAP, which only supports files from HOT2000 version 11.3 or later.

When the EGHD was filtered for records meeting these requirements, $6472 \mathrm{SD}$ and $\mathrm{DR}$ records were found. The list of selection parameters for sampling the new archetypes are provided in Table 1 . These parameters represent the factors that affect the performance of houses in each region. These suitable ranges for the selection parameters are identified based on the number of available house files in the EGHD, parameters of each house file, and the regional characteristics of new houses. The selection parameters was used to create a subset of HOT2000 files. The subset was used to randomly select the archetypes.

Table 1: Selection parameters.

\begin{tabular}{|c|c|}
\hline Parameter & Range \\
\hline $\begin{array}{l}\text { Housing } \\
\text { market }\end{array}$ & $\begin{array}{l}\text { Atlantic (AT), Quebec (QC), } \\
\text { Greater Toronto Area (GTA), } \\
\text { North and East Ontario (ON), } \\
\text { Prairies (PR), British Columbia } \\
\text { Lower Mainland (BC-LM), } \\
\text { British Columbia Interior } \\
(B C-I N T), \text { Territories (North) }\end{array}$ \\
\hline House type & $\begin{array}{l}\text { Single detached (SD), Double and } \\
\text { Row (DR) }\end{array}$ \\
\hline $\begin{array}{l}\text { Construction } \\
\text { year }\end{array}$ & 2015 to 2018 \\
\hline Storeys & 1,2 , and 3 \\
\hline Floor area & $50 \mathrm{~m}^{2}$ to $450 \mathrm{~m}^{2}$ \\
\hline Glazing ratio & 0.05 to 0.35 \\
\hline $\begin{array}{l}\text { Foundation } \\
\text { type }\end{array}$ & $\begin{array}{l}\text { Basement, crawl space, walkout, } \\
\text { slab on grade }\end{array}$ \\
\hline Ceiling type & $\begin{array}{l}\text { Attic/hip, Attic/gable, Flat, Scis- } \\
\text { sor, Cathedral }\end{array}$ \\
\hline
\end{tabular}

Sampling Method. NRCan adapted the sampling approach developed by Swan et al. (2009) to reflect the available data. The methodology was as follows:

1. Randomly sorted the 6472 suitable EGHD records

2. Examined each of these records in turn and selected them for inclusion in the archetype according to the following requirements:

- Each region must have 15 single attached homes and 15 double/row homes
- Each region must include at least one home exhibiting each of the following criteria:

- One, two and three stories,

- Basement, crawl space, walkout, slab on grade foundation types,

- Attic/hip, attic/gable, flat, scissor and cathedral types.

- Each home must be constructed in 2015 or later; have a floor area between $50 \mathrm{~m}^{2}$ and $450 \mathrm{~m}^{2}$, and a window-to-wall ratio between 0.05 to 0.35 .

The random sort and sample procedure was repeated several times to ensure the results were consistent.

Limitations and Mitigation Strategies. The number of existing house files in the EGHD is currently not sufficient for the development of new archetypes in GTA, ON, and QC. As an interim measure, NRCan developed a methodology to identify proxy archetypes from other markets that can be used until more data is available. The proxy house methodology is as follows:

1. For homes constructed in the GTA, NRCan selected all of the available records (11 SD and 1 DR) with associated HOT2000 v11 files.

2. For the remaining homes, NRCan examined the broader EGHD, including records with HOT2000 v10 files. NRCan used the same sampling procedure described earlier to identify additional four detached and 14 double/row homes.

3. These v10 files were examined to identify key parameters including floor area, glazing ratio, ceiling type, foundation type, and number of stories.

4. NRCan then searched through the available version 11 files to find homes with similar characteristics. These homes are the proxy houses.

NRCan repeated the proxy-home approach for the North and Eastern Ontario market, where a single builders enthusiastic participation in the ESNH program significantly biases the available records. For QC, NRCan used the same approach with one exception instead of the EGHD, the Novoclimat database (TEQ, 2018), the equivalent of ESNH program in the province of QC, was used as the basis for identifying key characteristics.

While the proxy-house approach is imperfect, it is a reasonable approach to ensure that key housing characteristics (size, glazing ratio, foundation type, ceiling type) from a given region are faithfully represented. While the proxy-house approach does introduce significant error for efforts to understand asbuilt construction trends (for instance, wall assemblies and heating equipment used in Alberta cannot be expected to represent practices in Quebec), this uncertainty is less important for the intended scope assessment of proposed code changes. In that analysis the as-built construction trends are commonly replaced with minimums from a reference baseline, 
and the archetypes geometry and shape are predominately important.

NRCan is also optimistic that increased use of HOT2000v11 will increase the number of suitable records available for archetype development, and that future versions of the archetypes will replace the proxy-houses with regional examples.

Multi-unit residential buildings (MURB) including duplex, triplex and apartments, is a growing form for new houses across Canada. Currently no suitable records for the development of MURB archetypes are available in the EGHD. The current release of the new archetypes are for single detached and double/row houses. Future work will add other Part 9 buildings such as MURBs. The systematic approach used for the development of the new archetypes provides the required tools to update archetypes in future as new data and new housing forms are needed.

\section{Case Study}

Section 9.36 of the NBC (CCBFC, 2015) describes the energy efficiency requirements for housing ${ }^{1}$. There are two principle pathways to demonstrate compliance with Section 9.36: prescriptive and performance. Prescriptive provides minimum requirements for envelope component thermal resistance and performance, equipment efficiencies, construction of air barrier, etc. The performance path requires energy calculation, or building simulation, to demonstrate that a proposed design performs as well or better than a building with identical geometry built according to the prescriptive requirements. Thus, under the current code compliance requirements the prescriptive path dictates the performance levels to achieve.

It has been proposed that the first step in a new Canadian NBC energy step code be prescriptive which achieves annual energy savings over the current prescriptive requirements. To develop these new prescriptive requirements, it is beneficial to identify which building components contribute significantly to annual energy consumption. It is also beneficial to benchmark the performance of current-code requirements. Therefore, a case study was undertaken which utilizes HTAP, and the newly developed archetypes, to achieve the following objectives:

1. Benchmark current performance of codecompliant housing in Canada,

2. Identify major sources of energy consumption in code-compliant housing,

3. Analyze the efficacy of a proposed prescriptive requirement.

A benefit of using HTAP for this type of analysis is that both HTAP and HOT2000 directly output annual building envelope heat loss by component group (windows, walls, etc.). Other building simulation

\footnotetext{
${ }^{1}$ And buildings up to three-storeys with floor areas less than $600 \mathrm{~m}^{2} /$ storey.
}

tools typically require additional post-processing to group envelope heat loss by component.

For this case study, all 240 archetypes were considered. The NBC code-compliance ruleset within HTAP was used to modify the archetype input files to comply with NBC Subsection 9.36.5 reference building requirements. These requirements dictate building operation schedules and setpoints. The reference building was assumed to use a heat recovery ventilator (HRV) and the envelope thermal resistances permitted in Subsection 9.36.2. HTAP was also used to impose code-compliant electric baseboard heating and electric hot water systems to all archetypes.

\section{Results and Discussion}

\section{Current-Code Archetype Performance}

The BC Step Code (Province of British Columbia, 2017) uses energy intensity performance metrics to characterize compliance with each step. One metric used to characterize envelope performance is the thermal energy demand intensity (TEDI), which considers the annual space heating energy demands of a building due to envelope heat loss, internal and solar gains, and ventilation/infiltration air, normalized over the heated floor area of the building. TEDI was used in this case study to assess envelope performance of houses built to the 2015 NBC minimum requirements.

The mean annual TEDIs for each climate zone is provided in Table 2. Under current-NBC requirements, the average TEDIs ${ }^{2}$ are shown to increase with number of HDD.

\section{Table 2: Average archetype TEDI by climate zone.}

\begin{tabular}{|l|l|l|}
\hline $\begin{array}{l}\text { Climate } \\
\text { Zone }\end{array}$ & $\begin{array}{l}\text { Average } \\
\text { TEDI } \\
{\left[\mathbf{k W h} / \mathbf{m}^{2}\right]}\end{array}$ & $\begin{array}{l}\text { Number of } \\
\text { Archetypes }\end{array}$ \\
\hline 4 & 38 & 30 \\
\hline 5 & 51 & 51 \\
\hline 6 & 60 & 99 \\
\hline $7 \mathrm{~A}$ & 82 & 30 \\
\hline $7 \mathrm{~B}$ & 83 & 29 \\
\hline 8 & 236 & 1 \\
\hline
\end{tabular}

The diversity contained within the new archetypes provides the opportunity to analyze how performance intensity metrics vary with built form. Rosenberg et al. (2015) previously stated that a challenge associated with building energy intensity targets is that it is difficult to define suitable and equitable targets across different built forms. This can can be seen by the distribution of the case study TEDIs, plotted in Figure 1.

The TEDI values in Figure 1 have sample standard deviations between $14 \mathrm{kWh} / \mathrm{m}^{2}$ and $33 \mathrm{kWh} / \mathrm{m}^{2}$.

\footnotetext{
${ }^{2}$ Currently there is only one archetype for Climate Zone 8. Housing data for this region is limited, and future archetype development will seek out more arctic housing data.
} 


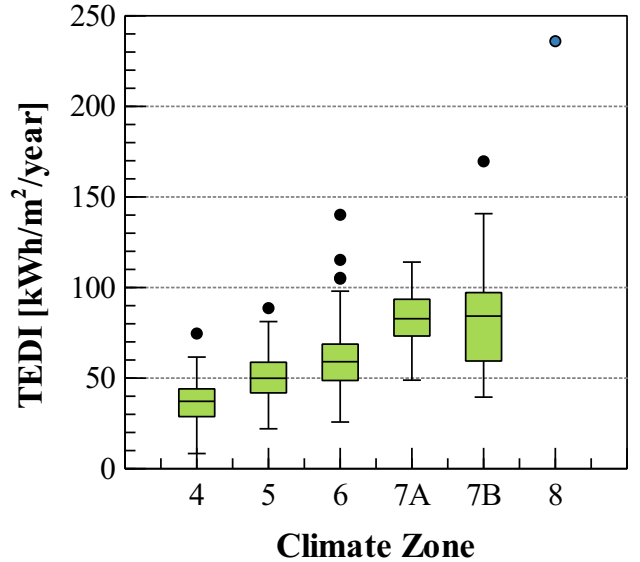

Figure 1: Code-compliant archetype space heating energy consumption.

Charron (2018) previously compared the TEDI performance of six archetypes against their targets in the BC Energy Step Code. They also found significant variation of TEDI performance within a prescribed climate, where building envelope thermal requirements were consistent for all archetypes.

Figure 2 plots the TEDI versus heated floor area for the code-compliant archetypes in Climate Zones 4 to 7B. The general trend is increasing TEDI with heated floor area.

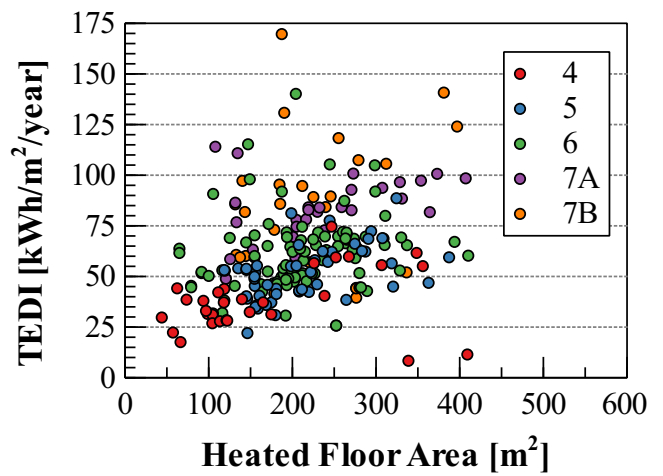

Figure 2: Code-compliant archetype TEDI versus heated floor area.

A least squares linear regression was performed for each climate group in Figure 2. The $R^{2}$ values were found to be between 0.01 and 0.23 indicating significant scatter of the data.

Figure 3 plots the variation of archetype TEDI performance, grouped by housing type: SD, and DR. Recall that for each housing market, an equal amount of SD and DR building types were defined.

The TEDI values of the SD archetypes are shown to be higher than DR archetypes. DR buildings typically have less exposed building envelope area per heated floor, reducing heating demands compared to a similarly sized SD building. The code implications of this is that if a single TEDI value is for all housing types, builders of DR housing are less incentivized and may be slower at adopting innovative efficient

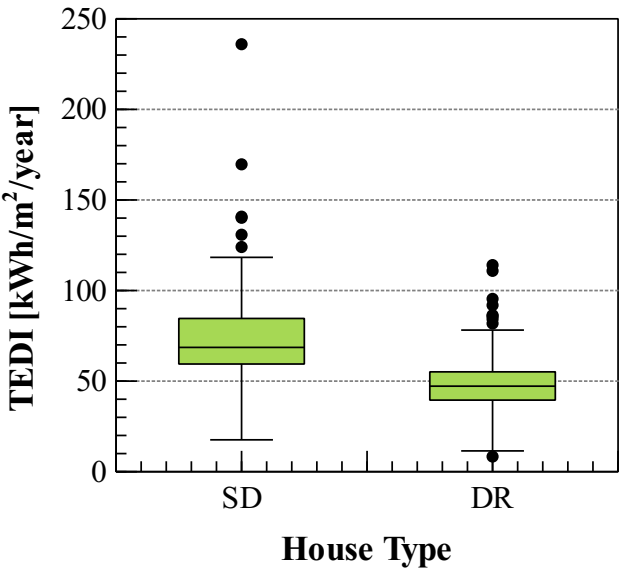

Figure 3: TEDI of single-detached and double/row archetypes.

technologies.

To identify candidate envelope components for performance improvement, HTAP simulation output was re-analyzed to determine the shares of total envelope heat loss by component for each climate zone, provided in Table 3 . These shares were determined by dividing the sum of component annual heat loss for each archetype in a climate zone by the sum of total annual envelope heat loss for each archetype.

Table 3: Share of total envelope heat loss by component.

\begin{tabular}{|l|l|l|l|l|l|l|}
\hline \multirow{2}{*}{ Group } & 4 & 5 & 6 & $7 \mathrm{~A}$ & $7 \mathrm{~B}$ & 8 \\
\hline \hline Fdn. & $11 \%$ & $18 \%$ & $20 \%$ & $14 \%$ & $18 \%$ & $4 \%$ \\
\hline Ceiling & $7 \%$ & $6 \%$ & $6 \%$ & $6 \%$ & $6 \%$ & $12 \%$ \\
\hline Doors & $5 \%$ & $5 \%$ & $4 \%$ & $4 \%$ & $4 \%$ & $2 \%$ \\
\hline $\begin{array}{l}\text { Exposed } \\
\text { Floors }\end{array}$ & $1 \%$ & $2 \%$ & $2 \%$ & $2 \%$ & $1 \%$ & $5 \%$ \\
\hline Walls & $31 \%$ & $25 \%$ & $28 \%$ & $27 \%$ & $27 \%$ & $30 \%$ \\
\hline Windows & $30 \%$ & $25 \%$ & $20 \%$ & $23 \%$ & $18 \%$ & $21 \%$ \\
\hline Inf/Vent & $15 \%$ & $18 \%$ & $20 \%$ & $24 \%$ & $26 \%$ & $25 \%$ \\
\hline
\end{tabular}

Fdn: Foundation

Inf/Vent: Infiltration \& ventilation

Table 3 indicates that under current-code prescriptive requirements the significant locations for envelope heat loss are walls, windows, and infiltration/ventilation in all Canadian climate zones. Therefore, the most significant increases in current-code building envelope performance would be realized by considering these envelope components.

\section{Performance Improvements from Airtightness}

The 2015 NBC currently assumes a whole-building envelope airtightness of $2.5 \mathrm{ACH} @ \Delta \mathrm{P}=50 \mathrm{~Pa}$ as the nominal airtightness of current housing and small buildings. Increasing airtightness requirements of building envelopes can potentially yield relatively high returns at lower incremental cost compared to other building envelope improvements. To explore the efficacy of airtightness increases on improving en- 
ergy performance, two airtightness levels were considered: 1.5 and $0.6 \mathrm{ACH} @ \Delta \mathrm{P}=50 \mathrm{~Pa}$. The 1.5 $\mathrm{ACH}$ target is aligned with the voluntary Canadian R-2000 housing standard that has been active for four decades (NRCan, 2012). The 0.6 ACH target was selected to align with the Passive House standard (PHI, 2015).

Each of the new archetypes were simulated in HTAP using the NBC code-compliance ruleset, and the modified airtightness levels. The ruleset default value is $2.5 \mathrm{ACH} @ \Delta \mathrm{P}=50 \mathrm{~Pa}$. HOT2000 simulates airtightness and infiltration using the AIM-2 empirical model developed by Walker and Wilson (1990). AIM-2 uses a power law formulation (Walker et al., 1998) to characterize building leakage, where the flow coefficient and exponent of the formulation are typically determined from fan depressurization tests. If only the $\mathrm{ACH} @ \Delta \mathrm{P}=50 \mathrm{~Pa}$ is provided to HOT2000 a flow exponent of 0.67 is assumed, which is a typical value for housing (Walker and Wilson, 1990).

Figure 4 plots the distribution of code-compliant archetype annual space heating demand savings from decreasing envelope air leakage from 2.5 ACH to 1.5 and 0.6 ACH. At 1.5 ACH, the average annual savings across the archetypes is $11 \%$. When the leakage is reduced to $0.6 \mathrm{ACH}$, the average savings increases to $21 \%$.
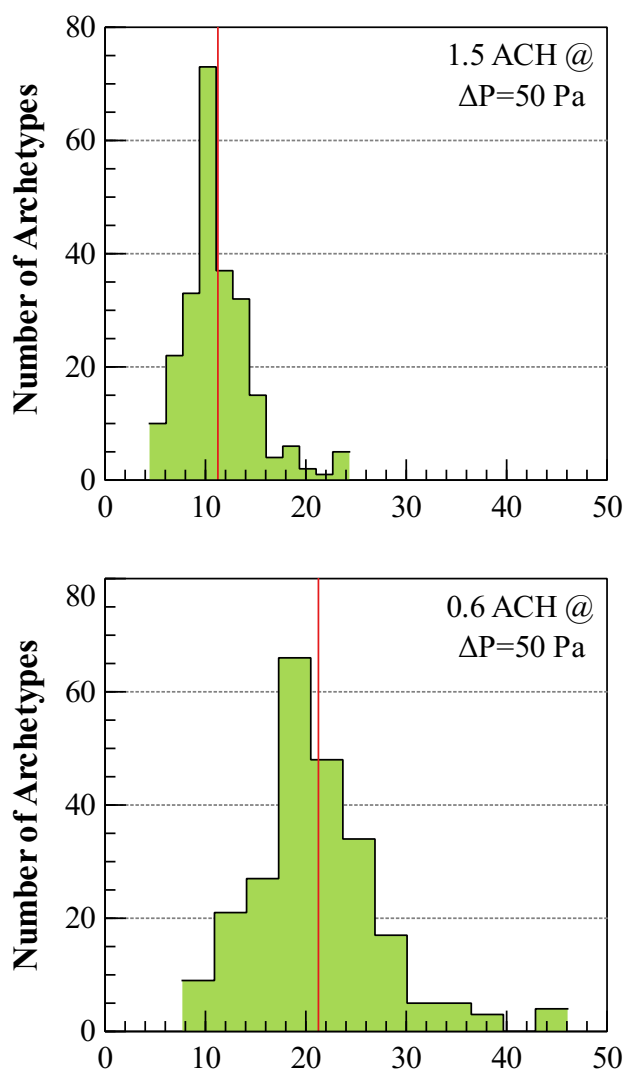

Annual Space Heating Demand Reduction [\%]

Figure 4: TEDI of single-detached and double/row archetypes.
Since the new archetypes capture the wide variety of built forms, it is possible to identify energy conservation measures which not only achieve desired performance nominally, but are also robust. For example, Figure 4 shows that at $0.6 \mathrm{ACH}$ the annual energy savings has greater variance compared to $1.5 \mathrm{ACH}$. The sample standard deviations of the savings is $7 \%$ and $4 \%$, respectively. A conclusion may be drawn that while $0.6 \mathrm{ACH}$ saves more energy on average, the \% savings associated with $1.5 \mathrm{ACH}$ are more consistent across different built forms and climates, and therefore more robust.

\section{Conclusion}

This paper describes the housing technology assessment platform, an optimization tool for building design, and its application for impact analysis of energy efficiency measures and advanced mechanical systems for residential building code in Canada. HTAP builds upon traditional energy simulation. It uses new approaches, data sets and methods to optimize building design. Therefore, HTAP can make code analysis faster, more regional and more comprehensive.

A case study was conducted using HTAP and the newly-developed housing archetypes. Rulesets built into HTAP modified archetype envelope components and equipment to comply with the 2015 National Building Code of Canada. Annual simulations of these archetypes show that the thermal energy demand intensity performance of current-code buildings varies significantly by climate and built form. There is also significant scatter of current housing TEDI performance. Setting a single TEDI requirement per climate zone would create uneven design change requirements for Canadian builders, and highlights the potential challenges of adopting absolute TEDI targets for performance-based codes which are currently being considered in Canada. Future work will examine how TEDI may be used in requlation and code to promote high-performing envelopes.

HTAP was also used to analyze the efficacy of increasing code-reference building envelope airtightness. The results demonstrate that adopting 1.5 and $0.6 \mathrm{ACH} @ \Delta \mathrm{P}=50 \mathrm{~Pa}$ nominally reduces space heating demand by $11 \%$ and $21 \%$, respectively. The variety of built forms represented in the new archetypes also provide a useful methodology for identifying robust energy conservation solutions. For the case considered here, the 1.5 ACH airtightness was shown to have more consistent energy savings performance across the archetypes compared to $0.6 \mathrm{ACH}$.

\section{Acknowledgment}

Authors are grateful for the funding provided by Natural Resources Canada through the Office of Energy Research and Development (OERD). 


\section{References}

Amann, J. T. (2014). Energy codes for ultra-lowenergy buildings. American Council for an EnergyEfficient Economy. Washington DC (USA).

Asaee, S. R., V. I. Ugursal, and I. Beausoleil-Morrison (2019). Development and analysis of strategies to facilitate the conversion of Canadian houses into net zero energy buildings. Energy Policy 126, 118130 .

ASHRAE (2014). Standard Method of Test for the Evaluation of Building Energy Analysis Computer Programs (ANSI/ASHRAE Standard 140-2014). ASHRAE.

CCBFC (2015). National building code of Canada. Canadian Commission on Building and Fire Codes, National Research Council. Ottawa, ON (Canada).

Charron, R. (2018). A proposed alternative to the $\mathrm{BC}$ energy step code targets. In Proceedings of the eSim 2018 Conference. Montréal, QC (Canada), 9-10 May 2018.

Environment and Climate Change Canada (2016). Pan-Canadian Framework on Clean Growth and Climate Change: Canadas plan to address climate change and grow the economy. Environment and Climate Change Canada. [Accessed: 2018-03-30].

ESRU (2018). ESP-r, Energy Systems Research Unit, Department of Mechanical Engineering, University of Strathclyde.

Haltrecht, D. and K. Fraser (1997). Validation of HOT2000 using HERS BESTEST. In Proceedings of the Building Simulation, Volume 97, pp. 8-10. Prague (Czech Rep.), 8-10 September 1997.

NRCan (2012). 2012 R-2000 standard, Natural Resources Canada: Office of Energy Efficiency. Available online at www.nrcan.gc.ca/sites/www. nrcan.gc.ca/files/oee/files/pdf/2012\%20R2000\% 20Standard\%20EN.pdf. [Accessed: 2019-01-31].

NRCan (2018a). Local energy efficiency partnerships (LEEP), Natural Resources Canada: CanmetENERGY-Ottawa. Available online at www.nrcan.gc.ca/energy/efficiency/housing/leep/ 17338. [Accessed: 2019-01-15].

NRCan (2018b). EnerGuide in Canada, Natural Resources Canada: Office of Energy Efficiency. Available online at www.nrcan.gc.ca/energy/products/ energuide/12523. [Accessed: 2018-03-30].

NRCan (2018c). HOT2000, Natural Resources Canada: Office of Energy Efficiency. Available online at www.nrcan.gc.ca/energy/efficiency/homes/ 20596. [Accessed: 2018-03-30].
Parekh, A. (2005). Development of archetypes of building characteristics libraries for simplified energy use evaluation of houses. In Proceedings of the Ninth International IBPSA Conference. Montréal, QC (Canada), 15-18 August 2005.

Parekh, A., R. Charron, S. Poirier, and L. Roux (2018). Testing of HOT2000 version 11 in accordance with ASHRAE standard 140-2014. In Proceedings of the eSim 2018 Conference. Montréal, QC (Canada), 9-10 May 2018.

Perry, C. (2018). Pathways to zero energy buildings through building codes. American Council for an Energy-Efficient Economy. Washington DC (USA).

PHI (2015). Passive house requirements, Passive House Institute. Available online at www.passiv. de/en/. [Accessed: 2019-01-31].

Proskiw, G. (2011). Cost and benefit analysis of proposed changes for energy efficiency in housing and small building in the National Building Code, Report prepared for Canadian Codes Centre, National Research Council.

Province of British Columbia (2017). Energy step code building beyond the standard, Province of British Columbia: Building and Safety Standards Branch. Available online at www.energystepcode. ca/. [Accessed: 2019-01-15].

Rosenberg, M., J. Zhang, R. Hart, and R. Athalye (2015). Roadmap for the Future of Commercial Energy Codes. Pacific Northwest National Laboratory. [Accessed: 2019-01-30].

Swan, L. G., V. I. Ugursal, and I. Beausoleil-Morrison (2009). A database of house descriptions representative of the Canadian housing stock for coupling to building energy performance simulation. Journal of Building Performance Simulation 2(2), 75-84.

TEQ (2018). Novoclimat, Transition Énergétique Québec. Available online at www.novoclimat.ca/. [Accessed: 2019-01-31].

Walker, I. and D. Wilson (1990). The Alberta Air Infiltration Model: AIM-2. The University of Alberta.

Walker, I. S., D. J. Wilson, and M. H. Sherman (1998). A comparison of the power law to quadratic formulations for air infiltration calculations. Energy and Buildings 27(3), 293-299.

Wills, A., I. Beausoleil-Morrison, and V. I. Ugursal (2016). Evaluation of source net-zero performance for residential community-scale retrofit photovoltaic systems in Canadian locations. In Proceedings of the eSim 2016 Conference. Hamilton, ON (Canada), 3-4 May 2016. 